\title{
Experience-Dependent Modifications in MAP2 Phosphorylation in Rat Olfactory Bulb
}

\author{
Benjamin D. Philpot, ${ }^{1}$ Jae H. Lim, ${ }^{1}$ Shelley Halpain, ${ }^{2}$ and Peter C. Brunjes ${ }^{1}$ \\ 1 University of Virginia, Department of Psychology, Charlottesville, Virginia 22903, and ${ }^{2}$ The Scripps Research Institute, \\ Department of Cell Biology, La Jolla, California 92037
}

\begin{abstract}
Microtubule-associated protein 2 (MAP2) is a neuron-specific cytoskeletal protein, enriched in dendrites and cell bodies, that helps determine dendritic shape. MAP2 regulates microtubule stability in a phosphorylation-dependent manner. The present study used immunocytochemistry with phosphoepitope-specific and phosphorylation state-independent antibodies to examine experiencedependent changes in MAP2 expression during postnatal development of the olfactory bulb. Our results demonstrate that immunoreactivity reflecting total MAP2 expression reaches a maximal level by postnatal day 20 (P20). The degree of staining for phosphoindependent forms of MAP2 is relatively unaffected by blocking odorant passage to one half the nasal epithelium via unilateral naris closure, a manipulation that attenuates physiological activity in the bulb. However, olfactory restriction from P1 dramatically reduces immunoreactivity for antibody AP18, which recognizes MAP2 only when phosphorylated on Ser ${ }^{136}$. Quantification of staining in the granule cell layer indicates that the great-
\end{abstract}

Cellular morphology is determined by the structural stability of cytoskeletal proteins. One such neuronal component, microtubuleassociated protein 2 (MAP2), is enriched in dendrites and cell bodies (Bernhardt and Matus, 1984; Tucker et al., 1988) in which it stabilizes polymerized tubulin and may regulate both microtubule spacing and the cross-linking of actin filaments (Matus, 1988). Suppression of MAP2 expression in cultured neurons inhibits neurite outgrowth and reduces neurite number (Caceres et al., 1992; Sharma et al., 1994), suggesting that MAP2-mediated regulation of microtubules is important for dendrogenesis.

Microtubules exhibit the property of dynamic instability both in vitro and in vivo. This process is regulated by MAP2 and other MAPs in a phosphorylation state-dependent manner. MAP2 has multiple phosphorylation sites for a variety of serine- and threonine-directed protein kinases and phosphatases (Sloboda et al., 1975; Theurkauf and Vallee, 1983; Schulman, 1984; Goto et al., 1985; Yamamoto et al., 1988; Walaas and Nairn, 1989; Brugg and Matus, 1991; Illenberger et al., 1996). MAP2 phosphorylation in vitro inhibits its ability to promote microtubule assembly (Jameson and Caplow, 1981; Murthy and Flavin, 1983;

\footnotetext{
Received June 18, 1997; revised Sept. 18, 1997; accepted Sept. 25, 1997.

This work was supported by National Research Service Award MH11068 (B.D.P.), NIDCD Grant DC-00338 (P.C.B.), and National Institutes of Health Grant MH50861 (S.H.). We give special thanks to Amy Batinica for technical assistance.

Correspondence should be addressed to Dr. Peter C. Brunjes, 102 Gilmer Hall, Department of Psychology, University of Virginia, Charlottesville, VA 22903.

Dr. Philpot's present address: Department of Neuroscience and Howard Hughes Medical Institute, Brown University, Box 1953, Providence, RI 02912.

Copyright (C) 1997 Society for Neuroscience $0270-6474 / 97 / 179596-09 \$ 05.00 / 0$
}

est difference (64\%) between control and experimental bulbs occurs after occlusion from P1 to P30 compared with animals deprived from P1 to P10 or P1 to P20. The shift in MAP2 phosphorylation occurs even when deprivation is delayed until P30, after the sensitive period for experience-dependent changes in bulb volume. Thus, the degree of the phosphorylation shift depends on the duration but not the time of onset of naris closure.

Because staining for phosphorylation-independent forms of MAP2 is unchanged by naris closure, the total amount of the protein per unit area is probably not significantly altered. However, the large reductions of AP18-immunoreactivity in the bulb after olfactory restriction suggest that there is an activitydependent stimulation of MAP2 phosphorylation.

Key words: activity-dependent; AP18; calcineurin; dendrite; HM-2; microtubule; naris closure; sensory deprivation; synaptic plasticity

Yamamoto et al., 1983), although in vivo the microtubule binding affinity of MAP2 may vary with the phosphorylation site (Brugg and Matus, 1991).

Activity-dependent processes of dendritic organization may be regulated, in part, by MAP2 phosphorylation. For example, exposure to light after dark-rearing dephosphorylates MAP2 within kitten visual cortex (Aoki and Siekevitz, 1985), suggesting perhaps a role for MAP2 in stabilizing dendrites that form functional synapses. In the hippocampus, depolarizing conditions increase MAP2 phosphorylation (Fukunaga et al., 1992; DiazNido et al., 1993). MAP2 phosphorylation is bidirectionally controlled by calcium and glutamate receptor-mediated events. Specifically, glutamatergic activation of hippocampal metabotropic receptors rapidly stimulates phosphorylation, whereas NMDA receptor activation stimulates sustained dephosphorylation (Halpain and Greengard, 1990; Quinlan and Halpain, 1996a). Furthermore, the bidirectional control of phosphorylation, at least in the hippocampus, emerges postnatally, because glutamate stimulates only increased phosphorylation during early postnatal life (Quinlan and Halpain, 1996b).

The olfactory bulb is a unique region for studying activitydependent regulation of MAP2 phosphorylation. MAP2 expression increases substantially in the postnatal bulb (Crandall and Fischer, 1989). Interestingly, embryonic forms of MAP2 persist in the adult bulb, perhaps to support the unique neuronal turnover that occurs throughout life (Altman, 1969; Kaplan and Hinds, 1977; Kaplan et al., 1985; Viereck et al., 1989; Lois and AlvarezBuylla, 1994). The data outlined above suggest that neural activity might regulate MAP2 phosphorylation in the bulb. Bulb function 


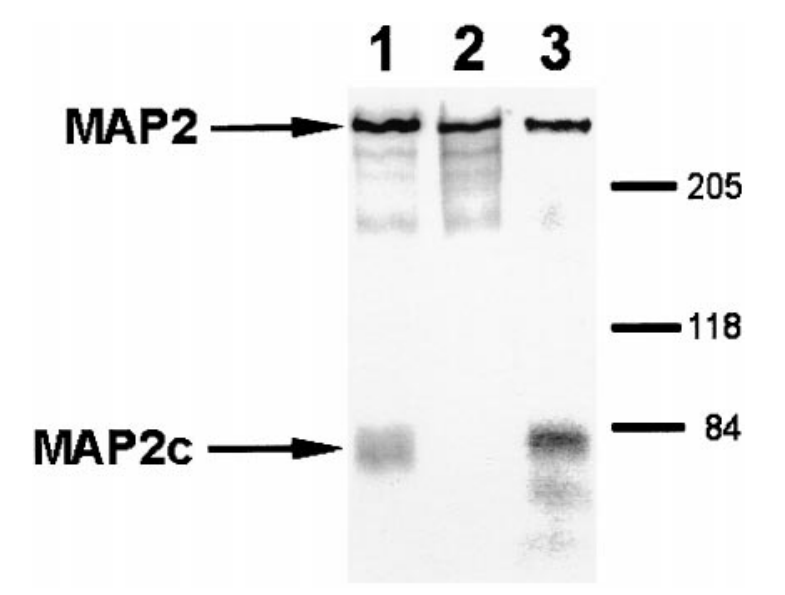

Figure 1. Immunoblot analysis of MAP2 isoforms present in adult rat olfactory bulb. Equal aliquots of total bulb homogenate were separated on $8 \%$ gels, transferred to nitrocellulose, and probed with the indicated antibodies against MAP2. Lane 1, Antibody HM-2, which recognizes all known isoforms of MAP2 independent of phosphorylation state; lane 2, antibody \#266, which recognizes only high molecular weight isoforms of MAP2 independent of phosphorylation state; lane 3, antibody AP18, which recognizes all known isoforms of MAP2 only when phosphorylated on $\mathrm{Ser}_{136}$. Positions of high molecular weight MAP2 and low molecular weight MAP2c are indicated by arrows. The fainter bands running below MAP2 and MAP2c likely represent proteolytic breakdown products. Positions of molecular weight markers (in kilodaltons) are given on the right.

is easily reduced by occluding an external naris and thereby blocking airflow through half of the nasal cavity (Iwahara et al., 1973; Gray and Skinner, 1988). Occlusion uncouples mitral cell responses from the respiratory cycle and reduces both spontaneous and odor-evoked activity (Philpot et al., 1997). Such changes are similar to the depolarization-dependent alterations observed in the hippocampal slice preparation and thus may cause shifts in MAP2 phosphorylation. The present study examined experiencedependent changes of MAP2 phosphorylation in the developing bulb using immunocytochemistry with phosphoepitope-specific and phosphoindependent antibodies.

\section{MATERIALS AND METHODS}

Subjects. Offspring of Long-Evans-hooded rats purchased from the Charles River Laboratories (Wilmington, MA) was used. Rats were housed in polypropylene cages $(40 \times 25 \times 16 \mathrm{~cm})$ and given food and water ad libitum. The colony room was maintained on a $16 / 8 \mathrm{hr}$ light/dark cycle. Litters were culled to 10 on postnatal day 1 (P1), the day after the day of birth. P1 subjects were anesthetized with hypothermia and underwent either unilateral occlusion of the right external naris via cautery or a sham manipulation consisting of cautery on the dorsal nose surface (Meisami, 1976). Pups were then warmed and returned to their mothers. Naris-occluded and sham-operated rat pups were examined at P10, P20, and P30. In addition, a second group received sham or naris cautery on P30 and was killed on P60. Staining using antibody 266 and the AP18 and calcineurin antibodies was examined in at least four animals for each developmental age and experimental condition. In addition, staining using AP18 and antibody 266 was examined in four animals that received naris cautery on P30 and were killed on P37. Finally, staining using the HM-2 antibody was examined in four experimental animals after closure from P1 to P30. All experimental procedures passed review by the University of Virginia Animal Research Committee and met guidelines established by the National Institutes of Health.

Immunoblot preparation. Frozen olfactory bulbs from P30 rats were rapidly solubilized in boiling hot $1 \%$ SDS by sonification; $45 \mu \mathrm{g}$ aliquots were loaded onto $8 \%$ polyacrylamide gels, electrophoretically separated, and transferred to nitrocellulose. Membranes were incubated at room temperature for $60 \mathrm{~min}$ in Tris-buffered saline, $\mathrm{pH} 7.3$, containing $0.1 \%$ Triton X-100 and 4\% nonfat dry milk to block nonspecific binding. This buffer was used for all reagent dilutions and rinses between steps. Membranes were incubated for $2 \mathrm{hr}$ with primary antibody using the following dilutions: polyclonal antiserum 266, 1:2000; monoclonal antibody AP18 hybridoma culture medium supernatant, 1:500; and monoclonal antibody HM-2 (Sigma, St. Louis, MO), 1:2000. For the two monoclonal antibodies, membranes were incubated $1 \mathrm{hr}$ with rabbit anti-mouse IgG (Calbiochem, La Jolla, CA) as the secondary antibody. After a $2 \mathrm{hr}$ incubation with ${ }^{125} \mathrm{I}$-Protein A $(0.1 \mathrm{mCi} / \mathrm{ml}$; Amersham, Arlington Heights, IL), membranes were dried and exposed to a PhophorImager screen to detect antibody binding.

Tissue preparation and immunostaining. Subjects were given an overdose of barbiturates and were perfused intracardially with $0.1 \mathrm{M} \mathrm{PBS}, \mathrm{pH}$ 7.4, followed by Bouin's fixative. Brains were carefully dissected and post-fixed overnight in the Bouin's fixative. Brains were then dehydrated for $24 \mathrm{hr}$ in $70 \%$ ethyl alcohol, run through an ascending alcohol series, cleared in toluene, and embedded in paraffin. Twelve-micrometer-thick sections were cut in the coronal plane and mounted onto gelatin-coated slides. Sections were deparaffinized for $5 \mathrm{~min}$ in xylenes, rehydrated through a descending alcohol series, rinsed three times with $0.1 \mathrm{M}$ phosphate buffer (PB), and placed for $15 \mathrm{~min}$ in $3 \% \mathrm{H}_{2} \mathrm{O}_{2}$ to quench endogenous peroxidases. After three washes in $\mathrm{PB}$, sections were incubated for $1 \mathrm{hr}$ in $10 \%$ normal goat serum (NGS) in PB to prevent nonspecific staining. Sections were then incubated with one of four antibodies: a rabbit anti-MAP2 polyclonal antibody that preferentially recognizes the high molecular weight MAP2 isoforms and has a binding affinity that is unaffected by phosphorylation (1:5000; antibody \#266; Halpain and Greengard, 1990), a MAP2 monoclonal antibody that recognizes all known forms of MAP2 and is unaffected by phosphorylation (1:1000; clone HM-2; Sigma), a phosphorylation-specific mouse antiMAP2 monoclonal antibody directed against the AP18 isotope (1:500; Berling et al., 1994), or a rabbit anti-calcineurin polyclonal antibody that recognizes specifically both $\mathrm{A}$ and $\mathrm{B}$ subunits of rodent brain calcineurin (1:1000; Halpain et al., 1997). All antibodies and the avidin-biotin complex (ABC; Vector Laboratories, Burlingame, $\mathrm{CA}$ ) detection solutions were diluted in PB with $10 \%$ NGS to reduce nonspecific binding. Slides were incubated for $24-72 \mathrm{hr}$ at $4^{\circ} \mathrm{C}$, washed three times with $\mathrm{PB}$, and transferred into a solution containing biotinylated secondary antibodies (1:100; swine anti-rabbit or goat anti-mouse; Dako, Carpenteria, CA) for $1 \mathrm{hr}$. After three rinses in PB, slides were placed into an ABC solution (100 $\mu \mathrm{l}$ each of solutions A and B in $50 \mathrm{ml}$ solution) for $90 \mathrm{~min}$. After three washes in $\mathrm{PB}$, slides were treated for 15-25 min with diaminobenzidine (DAB) and $\mathrm{H}_{2} \mathrm{O}_{2}$ in Tris-buffered saline or $\mathrm{PB}, \mathrm{pH}$ 7.4. Slides were then dehydrated, cleared in xylenes, and coverslipped with DPX (BDH Chemicals, Poole, UK).

Control experiments, consisting of the same protocol but omitting exposure to the primary antibody, consistently resulted in the absence of staining. The specificity and characterization of the antibodies used in this study have been examined previously (Huber and Matus, 1984; Halpain and Greengard, 1990; Berling et al., 1994) (S. Halpain, L. Saffer, and A. Hipolito, unpublished observations), and the specificity of the MAP2 antibodies was further characterized in the present study (see Fig. 1).

Several precautions were taken to ensure that histological artifacts were minimized. For example, tissues from several groups were processed in parallel whenever possible. Furthermore, sections from each animal were subjected to several immunostaining techniques to determine which were consistent and maximal. For example, antibody dilutions and exposure durations were optimized for the most robust staining. Tissue samples from each subject were preincubated in various concentrations of Triton X-100 to increase antibody penetration, as well as in lower concentrations of NGS to prevent overblocking to demonstrate that antigenicity was maximal. Examinations of the effects of naris occlusion were facilitated by the fact that left to right comparisons could be made within single sections.

Quantification. Both right and left bulbs (i.e., the experimental bulb ipsilateral to the occluded naris and the contralateral control, respectively) were analyzed for the density of immunoreactivity. Quantification was performed in the granule cell layer because it was the region of lowest variability (e.g., see Fig. 2). Segments $600 \mu \mathrm{m}$ in length and spanning the entire width of the layer were selected. A microcomputerbased image analysis system (MCID; Imaging Research) was used to calculate the proportion of the stained area to the total test area [area fraction, $\left(A_{A}\right)$ ]. Images were consistently thresholded for each pair of bulbs such that all areas containing DAB reactions were black and the background was white, and visual inspection verified that all immunostaining was detected. The olfactory nerve layer, a region devoid of 




Figure 2. Photomicrograph depicting immunoreactivity for a phosphorylationindependent MAP2 antibody, antibody 266 , in a coronal section through the olfactory bulb of a P60 rat. MAP2-IR is absent in the olfactory nerve layer $(O N L)$ and subependymal zone $(S U B)$. MAP2-IR dendrites have extensive ramifications in neuropil of the glomerular layer $(G L M)$. The external plexiform layer $(E P L)$ is dense with MAP2-IR dendrites. Numerous MAP2-IR dendrites extend from the granule cell layer $(G C L)$, through the mitral cell layer $(M C L)$, and into the EPL. Scale bar, 300 $\mu \mathrm{m}$. dendrites, was used to define background staining. Threshold levels were individually set for each pair of bulbs to ensure all immunoreactivity was identified, and thresholding and light levels were unchanged in pairs of left and right bulbs. The image analysis system was calibrated to ensure that all staining was included in area fraction determinations while background staining was excluded. The difference in the area fraction of staining between bulbs was calculated with the following formula: $100 \times$ $\left(A_{A}\right.$ right bulb $-A_{A}$ left bulb) $/ A_{A}$ left bulb. Values from each section were averaged for each animal, and a mean was determined across animals. ANOVA was performed to test whether the dependent variable (difference in area fraction) varied as a function of age group and experimental condition (naris-occluded or sham-operated). The data were analyzed for main effects and for interactions. A post hoc test, Tukey's honestly significant difference, was used to probe for univariate variations. The significance level was defined as $p<0.05$. No statistical differences in staining were observed between left and right bulbs of nonoccluded subjects.

\section{RESULTS}

Figure 1 demonstrates that antibody HM-2 recognizes all known isoforms of MAP2, whereas antibody 266 recognizes only high molecular weight isoforms of MAP2. Both antibodies HM-2 and 266 recognize MAP2 independent of phosphorylation state. Antibody AP18 recognizes all known isoforms of MAP2 only when phosphorylated on $\operatorname{Ser}_{136}$. Because both the phosphorylationindependent and the phosphorylation-specific forms of MAP2 were examined, we have defined "MAP2-immunoreactivity" (IR) to refer to staining observed with the antisera directed against the phosphorylation-independent isoforms and "AP18-IR" to refer to staining observed with antiserum to the phosphorylationspecific AP18 epitope of the MAP2 isoform. Unless otherwise noted, characterization of phosphorylation-independent forms of MAP2 staining was made using antibody 266.

MAP2-IR was striking in the main olfactory bulb (Fig. 2). Staining was absent in the olfactory nerve layer and subependymal zones but present in all other layers. In general, MAP2-IR filled all glomeruli in the olfactory bulb (the site of synaptic contact between incoming olfactory nerve axons and central elements), was dense in the external plexiform layer, and was distributed evenly throughout the granule cell layer. Staining was restricted to dendrites and the perikaryal regions. There was no evidence of axonal or glial staining. Although no developmental changes in patterns of staining were observed, age-related increases in the density of staining did occur.

On P10, MAP2-IR dendrites had extensive arbors within glomerular neuropil (Fig. 3A). The dendritic arbors appeared to arise from mitral and juxtaglomerular cells and from cells in the external plexiform layer. Staining was most intense in the external plexiform layer. Laterally extending dendrites were more prevalent in the deeper half of the external plexiform layer. Although thick mitral cell dendrites were heavily labeled, only minimal staining was present within mitral cell somata. Deep to the mitral cell layer, MAP2-IR dendrites were observed extending from granule cells. The somata of most granule cells were labeled.

There was a marked increase in staining intensity from P10 to P20 (Fig. 3B). The external plexiform layer was divided into two zones, with more dense MAP2-IR in the deeper half than in the superficial half. Granule cell apical dendrites had intense MAP2IR. From P20 to P60, there was little change in MAP2-IR. Qualitatively there appeared to be a decrease in the intensity of MAP2-IR from P30 to P60 (Fig. 3C,D).

The pattern and amount of MAP2-IR were similar in right and left bulbs from both normal and naris-occluded rats in all age groups (Fig. 4). The percent difference in area fraction did not vary as a function of age $\left[F_{(3,24)}=2.188 ; p>0.05\right]$ or experimental treatment $\left[F_{(1,24)}=2.8 ; p>0.05\right]$.

The pattern of AP18-IR was similar to that of MAP2-IR, although AP18 staining was consistently sparser and lighter (compare photomicrographs in Fig. 5). Within individual glomeruli, AP18-IR was present along fewer dendrites compared with 

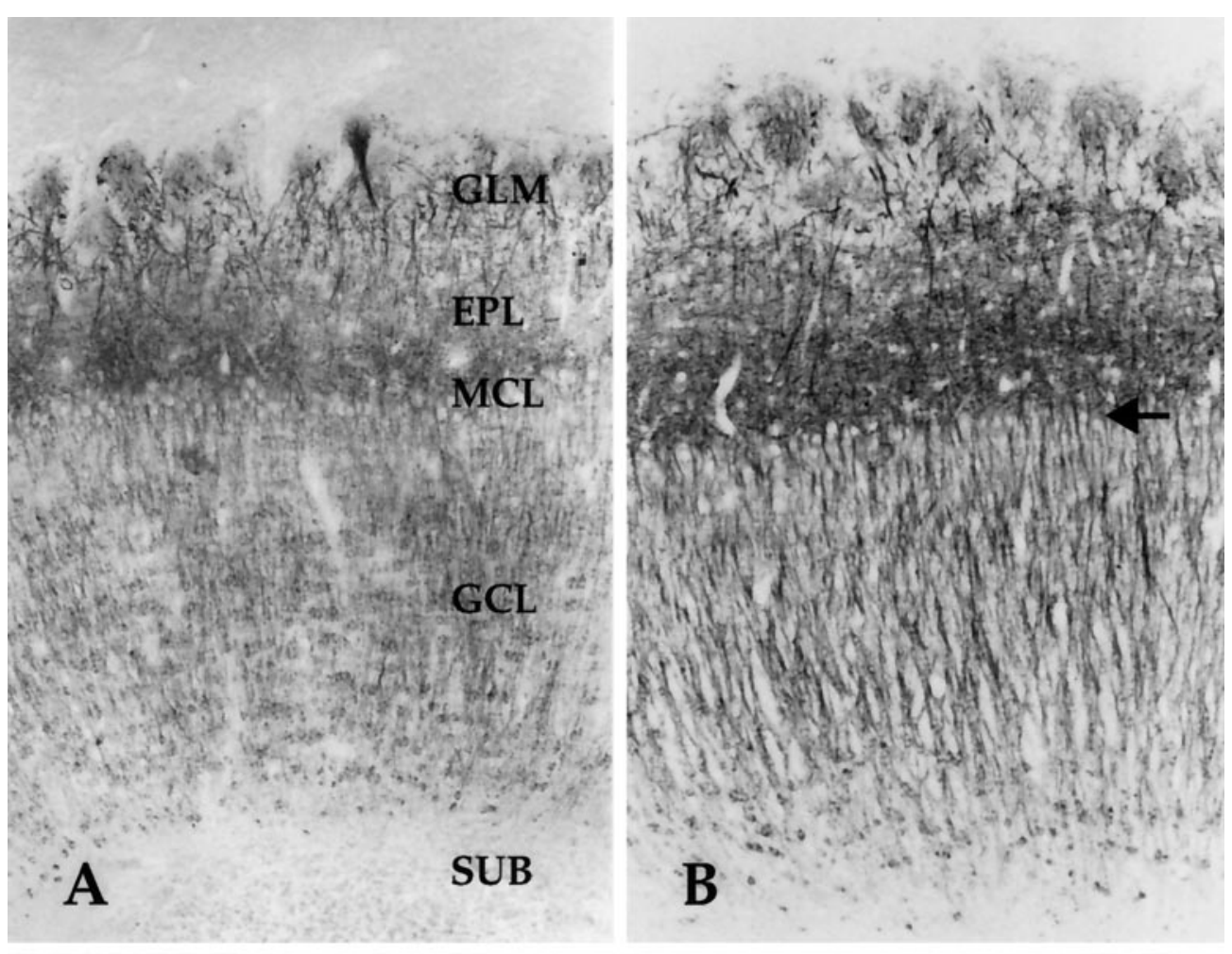

Figure 3. Photomicrographs depicting immunoreactivity for a phosphorylationindependent MAP2 antibody, antibody \#266, in coronal sections of the developing bulb. $A$, At P10, MAP2-IR dendrites have extensive arborizations in glomeruli, and the external plexiform layer contains numerous MAP2-IR dendrites. Granule cells have distinct MAP2-IR along their somatic periphery, and their dendrites are lightly labeled. $B$, At P20, MAP2-IR is most intense at this age. The deep half of the external plexiform layer generally has more labeling than does the superficial half. Granule cell dendrites are darkly immunoreactive. $C$, At P30, MAP2-IR has a distribution similar to that seen in the P20 bulb. $D$, At P60, the intensity of MAP2-IR has decreased slightly from that observed in the P30 bulb. Arrows mark the mitral cell layer. For abbreviations, see Figure 2. Scale bar, $200 \mu \mathrm{m}$.
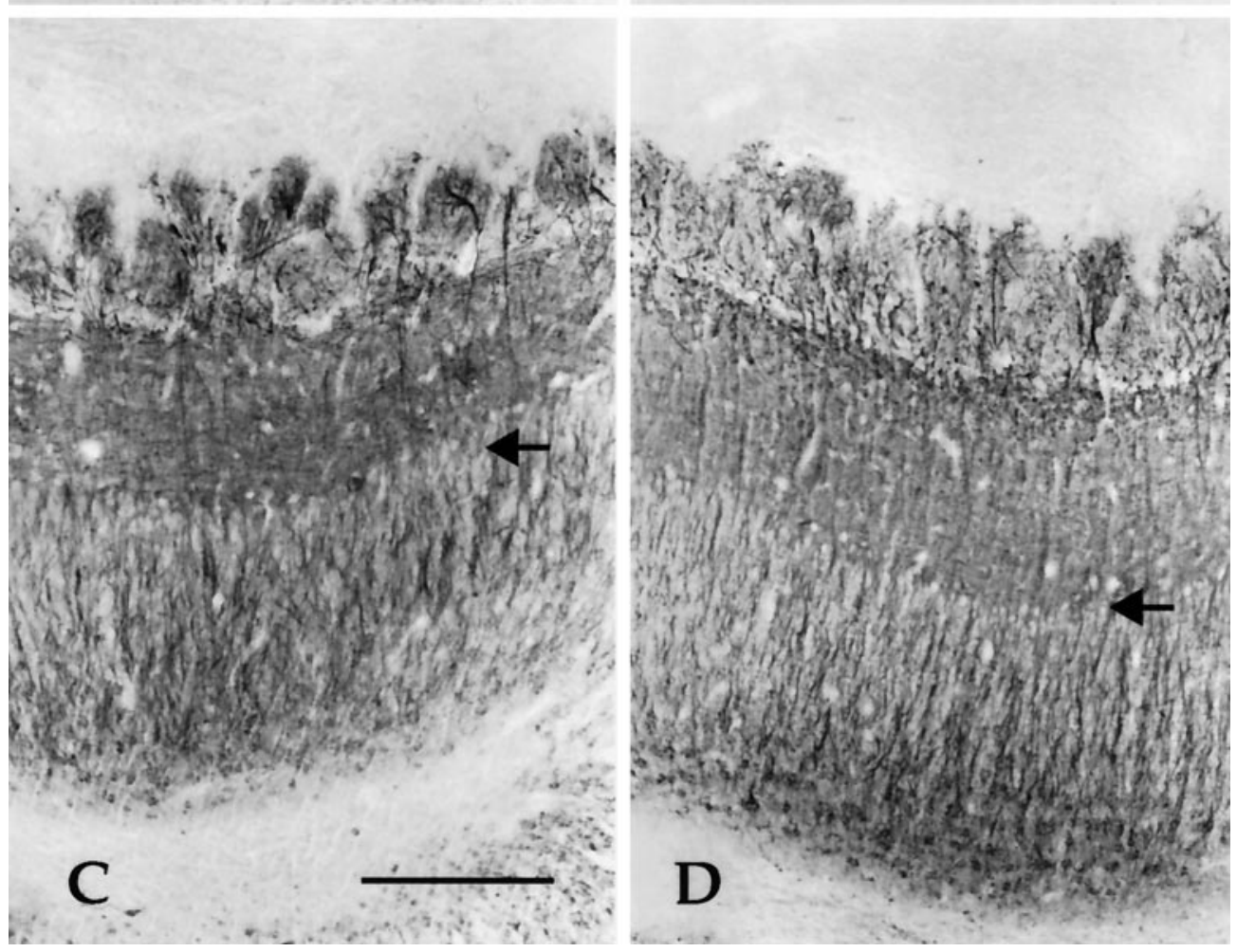

MAP2-IR. Laterally extending AP18-IR processes were common along the deep border of glomeruli. The degree of dendritic labeling in the external plexiform layer was quite variable. Generally, AP18-IR dendrites were most intense in the deep half of the external plexiform layer and throughout the granule cell layer (Fig. 6). There was no evidence of laterality of AP18-IR between right and left bulbs of sham-operated rats at any age during development (Fig. 7).
Although unilateral naris closure had no effect on MAP2-IR in the bulb, AP18-IR was dramatically affected by the manipulation (Fig. 6). Particularly, there was less AP18-IR in the granule cell layer of experimental bulbs compared with contralateral control bulbs. Staining in the granule cell layer was reduced in experimental bulbs in every animal measured, resulting in a significant effect of experimental condition $\left[F_{(1,23)}=108.8 ; p<0.0001\right.$; Figure 7]. Furthermore, the reduction varied as a function of age 




Figure 4. Graph depicting the mean percent difference ( \pm SEM) between left and right bulbs in the area fraction of MAP2-IR (phosphorylationindependent antibody 266) within the granule cell layer. In sham-operated animals $(S H A M)$, there is no difference between bulbs in MAP2-IR from $\mathrm{P} 10, \mathrm{P} 20, \mathrm{P} 30$, or P60 rats. In naris-occluded rats $(N O S X)$, there is also a negligible difference in MAP2-IR between bulbs from animals occluded from P1 to P10, P1 to P20, P1 to P30, or P30 to P60.

$\left[F_{(3,23)}=4.1 ; p<0.05\right]$, and there was a significant interaction between age and experimental condition $\left[F_{(3,23)}=5.0 ; p<0.01\right]$. Post hoc analysis indicated a significant reduction in AP18-IR in deprived bulbs from animals occluded from P1 to P20, P1 to P30, and $\mathrm{P} 30$ to $\mathrm{P} 60(p<0.05)$. The reduction in AP18-IR was related to the duration of occlusion: for example, rats occluded from P1 to $\mathrm{P} 30$ had a greater reduction in AP18 staining than did rats occluded from P1 to P10 $(p<0.05)$. Unlike many of the effects of naris closure in the olfactory bulb (Brunjes, 1994), the reduction in AP18-IR was not age-dependent; rats occluded from P30 to P60 had similar significant reductions in staining as did subjects occluded from P1 to P30.

In addition to the reductions in AP18-IR in the granule cell layer, there appeared to be fewer AP18-IR processes in the glomerular layer of experimental bulbs after naris closure, whereas AP18-IR in the external plexiform layer appeared unchanged by the manipulation (Fig. 6).

Because reductions in AP18-IR were observed with late- as well as early-onset occlusion, an additional set of experimental animals was examined to determine whether short periods of occlusion in older rats could alter the expression of AP18-IR. In rats occluded from $\mathrm{P} 30$ to $\mathrm{P} 37$, only small changes were observed; the mean percent difference in area fraction was $-4 \pm 7 \%$ for MAP2-IR and $-6 \pm 5 \%$ for AP18-IR. These data further suggest that the duration of occlusion, rather than the age of onset, is the major contributing factor to the loss of AP18-IR.

Although studies using antibody 266 demonstrated that the area fraction of staining for the high molecular weight forms of MAP2 was not altered after naris closure, the decrease in AP18-IR might be caused by a specific loss of the low molecular weight forms of MAP2 not detected by antibody 266. An antibody that recognizes all known forms of MAP2 and is phosphoindependent, the HM-2 antibody, was used to examine the possibility that reductions in AP18-IR were caused by a loss of low molecular weight forms of MAP2. HM-2 staining (Fig. 8) resembled staining using antibody 266. Moreover, the area fraction of staining using the HM-2 antibody was not altered in experimental bulbs in animals occluded from P1 to P30. The mean percent difference $( \pm$ SEM) in area fraction of HM-2 staining between bulbs was $3 \pm 5 \%$.
Because of the changes in AP18-IR that were observed after naris closure, the presence of calcineurin, an activity-dependent protein phosphatase that can dephosphorylate MAP2, was examined in the bulb. At all ages, calcineurin-IR was present in somatic profiles in the granule cell layer (Fig. 9), precisely the layer in which we observed reductions in AP18-IR. Faint labeling of granule cell dendrites was also observed. No quantitative changes in calcineurin-IR were observed in experimental bulbs after naris closure.

\section{DISCUSSION}

The present study demonstrates that olfactory experience modifies the phosphorylation state of MAP2 in the developing and adult rat olfactory bulb. Thirty days of olfactory restriction significantly reduce immunostaining with the phosphorylation-dependent antibody against MAP2 (AP18) in the granule cell layer of the bulb, whereas immunoreactivity using phosphorylation-independent MAP2 antibodies is unaffected. The fact that staining with the phosphorylation-independent antibodies against MAP2 is unchanged by naris closure suggests that the density of dendrites does not change after the manipulation but that there is a net decrease in the proportion of phosphorylated MAP2. The reduction in AP18 levels might be because of (1) a general decrease in phosphorylated MAP2 within all dendrites and somata, (2) a decrease in the number of dendrites and somata expressing phosphorylated MAP2, or (3) discrete losses of phosphorylated MAP2 within the dendritic organization.

Several nonexclusive possibilities might account for the reduction in AP18-IR after naris closure. There may be a reduction in the activity of one or more of the kinases that phosphorylate MAP2. Phosphorylation at $\operatorname{Ser}_{136}$ is required for the AP18 antibody to recognize all MAP2 isoforms (Berling et al., 1994). This epitope is phosphorylated in vitro by multiple proline-directed kinases, including mitogen-activated protein kinase (MAPK) (Berling et al., 1994). Although it is not yet known whether MAPK phosphorylates this site in vivo, the compound PD90859, which inhibits MAPK activation (Alessi et al., 1995), reduces basal and stimulated MAP2 phosphorylation in hippocampal slices (Quinlan and Halpain, 1996b). Furthermore, MAPK can be activated by synaptic activity (Murphy et al., 1994). Thus, MAPK is a strong candidate for a kinase that may contribute to AP18-IR in vivo. Interestingly, early unilateral naris closure prevents developmental increases in protein kinase $\mathrm{C}$ activity (Elkabes et al., 1993), and protein kinase $C$ has been shown in some cell types to stimulate the MAPK pathway (Cobb et al., 1991).

Alternatively, the loss of AP18-IR could be caused by an increase in phosphatase activity after naris closure. The calcium- and calmodulin-dependent protein phosphatase calcineurin dephosphorylates MAP2 in vitro (Goto et al., 1985; Yamamoto et al., 1988) and in hippocampal slices of both adult (Halpain and Greengard, 1990; Quinlan and Halpain, 1996a) and, to a lesser degree, neonatal rats (Quinlan and Halpain, 1996b). Data illustrated in Figure 9 indicate that calcineurin-IR is present in the granule cell layer, precisely the area in which experience-dependent reductions in AP18-IR occur. Hence, this phosphatase is a potential candidate for mediating the observed dephosphorylation.

Another possibility for the loss of AP18-IR may be that there is an increase in newly formed MAP2 that has yet to undergo phosphorylation. Enhanced MAP2 formation could occur if the rate of cell proliferation increases or if there is enhanced dendrogenesis. However, this possibility is less likely because dendritic morphology and the rate of cellular proliferation are ap- 
Figure 5. Photomicrographs depicting immunoreactivity for a phosphorylationindependent antibody to MAP2 $(A)$, antibody 266, and staining for the phosphoepitope-specific AP18 antiserum $(B)$ in adjacent coronal sections of bulbs from a P30 rat. $A$, Numerous dendrites in the glomerular layer contain MAP2-IR. Labeling of dendrites is particularly dense along the deep border of the glomerular neuropil. The external plexiform layer has dark immunoreactivity, and stained dendrites course from the external plexiform layer through the mitral cell layer. $B$, AP18-IR is generally much sparser than is staining for the phosphorylationindependent MAP2 antibody. For example, relatively few dendrites are labeled in glomeruli. Labeling is less dense in the external plexiform and granule cell layers as well. The arrow marks the mitral cell layer. For abbreviations, see Figure 2. Scale bar, $100 \mu \mathrm{m}$.
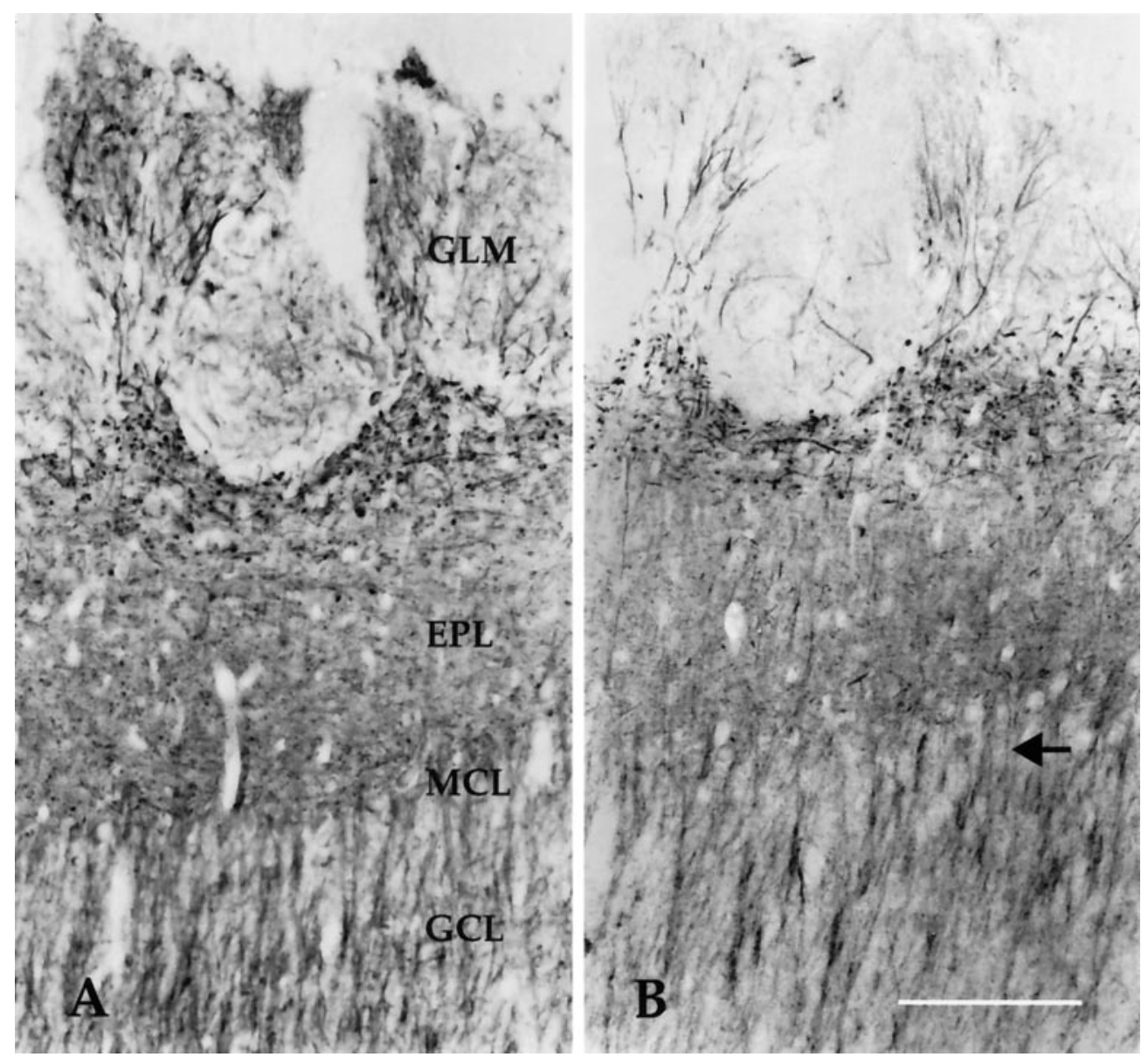

parently unchanged by naris closure (Frazier-Cierpial and Brunjes, 1989a,b) and, in addition, olfactory restriction attenuates overall protein synthesis (Korol and Brunjes, 1990).

In the visual system, experience-dependent shifts in MAP2 regulation correspond to a critical period of anatomical development. Aoki and Siekevitz (1985) demonstrated that cAMPinduced MAP2 phosphorylation in vitro is lower in the visual cortex of kittens reared in the dark compared with normal controls and that subsequent exposure to light after dark rearing increases cAMP-induced MAP2 phosphorylation. The results were interpreted to suggest that, in vivo, high levels of phosphorylation are conducive to dendritic plasticity. In addition, light is a sufficient stimulus to dephosphorylate MAP2, and this dephosphorylation may stabilize functional connections. The experience-dependent regulation of phosphorylation spans the critical period for the segregation of ocular dominance columns and does not occur in adults (Aoki and Siekevitz, 1985), although a loss of retinal activity in adult monkeys can reduce overall levels of MAP2 expression in cortical regions dominated by the deprived eye (Hendry and Bhandari, 1992).

Unlike the situation in the visual system, experience-dependent shifts in MAP2 phosphorylation in the olfactory bulb are not limited to early development. Our observations suggest naris closure induces a reduction in MAP2 phosphorylation that is dependent on the duration, but not the time of onset, of closure. Changes in AP18-IR are observed after $30 \mathrm{~d}$ of olfactory restriction, whether restriction begins on P1 or P30. There are many explanations for the differences observed between the two sensory modalities. For example, the continued expression of embry- onic MAP2 may conserve activity-dependent shifts of MAP2 phosphorylation in the adult olfactory system. Viereck et al. (1989) demonstrated that MAP2c persists in the adult rat olfactory bulb, whereas the isoform is present in low levels in other areas of the brain. In addition, the bulb maintains high levels of dendrogenesis and synaptogenesis throughout life (Farbman, 1992), features that slow considerably in the visual cortex with maturation. Activity-dependent regulation of MAP2 phosphorylation likely supports this unique neuronal plasticity. There is ongoing dendritic rearrangement within the bulb, because olfactory receptor neurons are constantly replaced (Farbman, 1992). Furthermore, interneurons generated in the anterior horn of the lateral ventricle are continually added to the bulb (Altman, 1969; Kaplan and Hinds, 1977; Kaplan et al., 1985; Lois and AlvarezBuylla, 1994). Thus, dendritic rearrangement occurs at a relatively high level in adults as well as in neonates.

Because previous studies have demonstrated that in vitro phosphorylated MAP2 is impaired in its ability to stabilize microtubules (Jameson and Caplow, 1981), high levels of MAP2 phosphorylation in the bulb may correlate with continual cytoskeletal reorganization. The reduction in MAP2 phosphorylation with naris closure may signify that the bulb has achieved a relatively stable state. The reduced afferent input after closure may not be conducive to dendritic reorganization. For example, naris closure reduces the rate of olfactory receptor neuron turnover in the epithelium (Farbman et al., 1988; Cummings and Brunjes, 1994), suggesting that less dendritic remodeling occurs in the glomerular neuropil. Perhaps neural activity after olfactory restriction is insufficient to support high levels of dendritic remodeling 

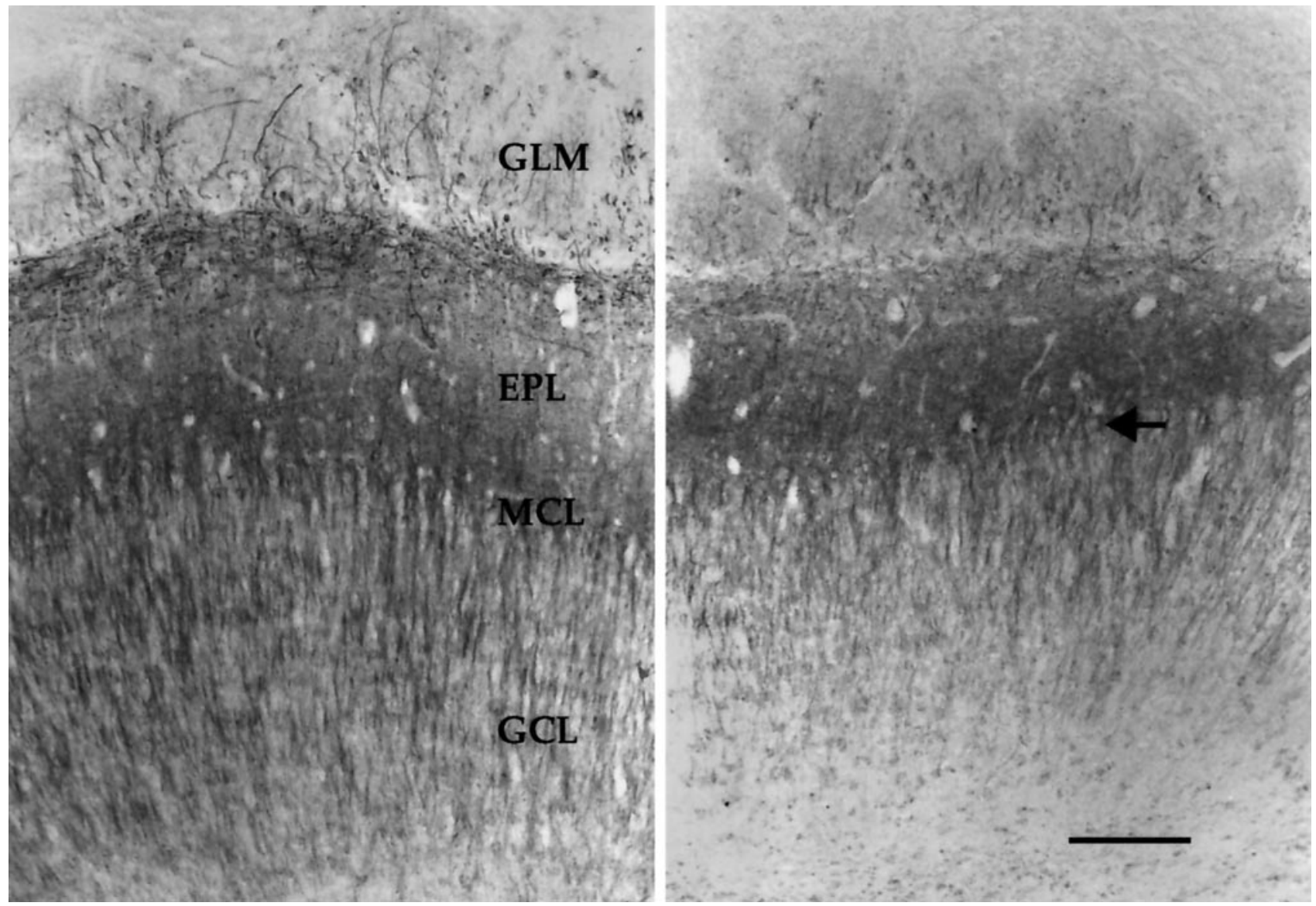

Figure 6. Photomicrographs demonstrating AP18-IR in coronal sections from control (left) and experimental (right) bulbs after unilateral naris closure. Left, AP18-IR dendrites are apparent as they project into glomeruli or extend laterally in superficial aspects of the external plexiform layer. AP18-IR is relatively dense in the external plexiform layer, and many dendrites in the granule cell layer are labeled. Right, AP18-IR is less intense in experimental bulbs. Fewer dendrites are labeled in the glomerular layer, and there is substantially less immunoreactivity of granule cell dendrites. The arrow marks the mitral cell layer. For abbreviations, see Figure 2. Scale bar, $100 \mu \mathrm{m}$.

throughout the bulb. Although reductions in AP18-IR were easily quantified only in the granule cell layer, qualitative observations suggest the decrease in AP18-IR may also occur in the glomerular layer (Fig. 6). However, differences in AP18-IR were not readily apparent in the external plexiform layer, suggesting that there might be regional specificity in the changes in MAP2 phosphorylation.

Physiological activity may be a critical regulator of MAP2 phosphorylation. In the hippocampus, depolarization can induce MAP2 phosphorylation (Fukunaga et al., 1992; Diaz-Nido et al., 1993). Recent data suggest that depolarization in the neonatal hippocampus results only in a net increase in MAP2 phosphorylation, whereas glutamatergic depolarization in adults induces a biphasic change in MAP2 phosphorylation (Quinlan and Halpain, 1996b). Because of the continued expression of embryonic MAP2 isoforms in the bulb, neuronal activity may maintain high levels of MAP2 phosphorylation in both the developing and adult bulb. Because previous data have shown that naris closure dramatically decreases physiological activity in the bulb (Iwahara et al., 1973; Gray and Skinner, 1988; Philpot et al., 1997), the attenuated MAP2 phosphorylation with olfactory restriction may result from reduced neural activity. Although there are many ways to explain the observed shift in phosphorylation, one possibility is that the high-frequency, rhythmic activity normally found in the olfactory bulb may trigger a variety of calcium-dependent

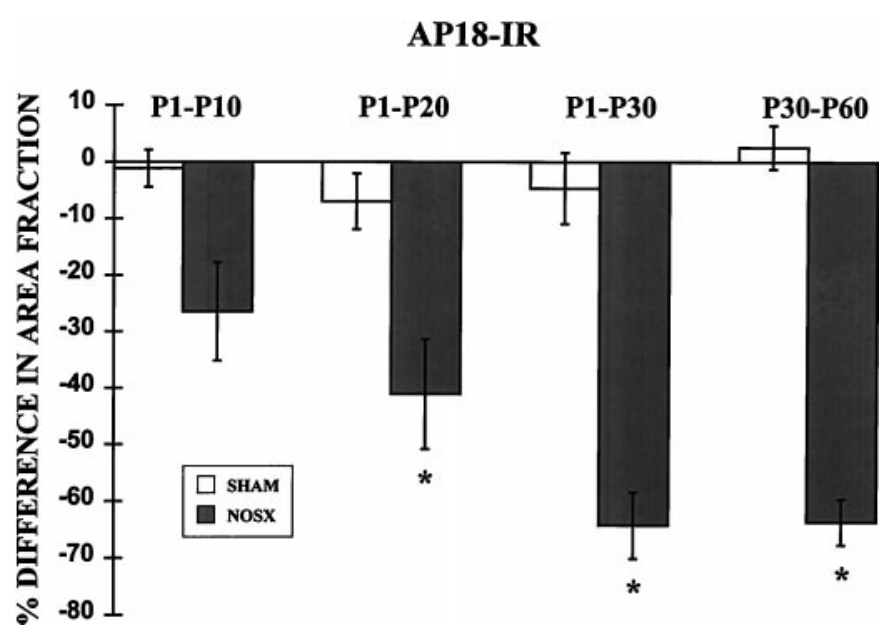

Figure 7. Graph of the mean percent difference ( \pm SEM) between left and right bulbs in the area fraction of AP18-IR within the granule cell layer. In sham-operated rats $(S H A M)$, there is a negligible difference between right and left bulbs in P10, P20, P30, and P60 rats. However, after naris closure (NOSX), the area fraction of the bulb containing AP18-IR in the granule cell layer is dramatically reduced in experimental bulbs after occlusion from $\mathrm{P} 1$ to $\mathrm{P} 20, \mathrm{P} 1$ to $\mathrm{P} 30$, or $\mathrm{P} 30$ to $\mathrm{P} 60$. Asterisks denote significant differences from zero $(p<0.05)$. Note the $y$-axis change from Figure 4. 




Figure 8. Photomicrograph depicting HM-2 staining in a coronal section from a P30 bulb. The HM-2 antibody is phosphorylation-independent and recognizes all known forms of MAP2. Note the absence of staining in the nerve layer and the particularly dense immunoreactivity in the deeper portion of the external plexiform layer. Staining patterns are similar to those found using antibody 266. For abbreviations, see Figure 2. Scale bar, $150 \mu \mathrm{m}$.

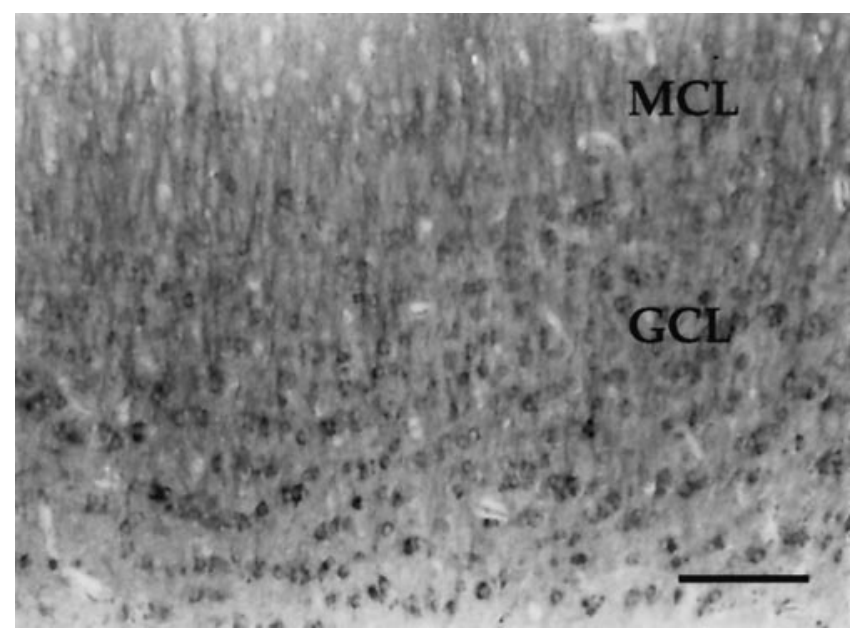

Figure 9. Photomicrograph depicting calcineurin-IR in a coronal section through the granule cell layer of a P20 bulb. Calcineurin-IR is located within somata but absent from the nucleus. There is some faint labeling of dendrites. For abbreviations, see Figure 2. Scale bar, $75 \mu \mathrm{m}$. kinases, such as MAPK, that use MAP2 as a substrate, whereas the low-frequency activity that follows naris closure (Philpot et al., 1997) may activate protein phosphatases, such as calcineurin, to dephosphorylate MAP2.

In sum, our data suggest that experience-dependent patterns of neural activity support relatively high levels of MAP2 phosphorylation in the bulb, because olfactory restriction, starting either before or after the sensitive period for experience-induced anatomical changes, causes a dramatic downregulation of MAP2 phosphorylation at the AP18 epitope. Although the present study detected substantial changes in the phosphorylation of $\operatorname{Ser}_{136}$ on MAP2, it is quite possible that additional phosphorylation state changes occur at other residues as well.

\section{REFERENCES}

Alessi DR, Cuenda A, Cohen P, Dudley DT, Saltiel A (1995) PD098059 is a specific inhibitor of the activation of mitogen-activated protein kinase kinase both in vitro and in vivo. J Biol Chem 270:27489-27494.

Altman J (1969) Autoradiographic and histological studies of postnatal neurogenesis. IV. Cell proliferation and migration in the anterior forebrain, with special reference to persisting neurogenesis in the olfactory bulb. J Comp Neurol 137:433-458.

Aoki C, Siekevitz P (1985) Ontogenetic changes in the cyclic adenosine $3^{\prime}, 5^{\prime}$-monophosphate-stimulatable phosphorylation of cat visual cortex proteins, particularly of microtubule-associated protein 2 (MAP 2): effects of normal and dark rearing and of the exposure to light. J Neurosci 5:2465-2483.

Berling B, Wille H, Roll B, Mandelkow EM, Garner C, Mandelkow E (1994) Phosphorylation of microtubule-associated proteins MAP2a,b and MAP2c at Ser136 by proline-directed kinases in vivo and in vitro. Eur J Cell Biol 64:120-130.

Bernhardt R, Matus A (1984) Light and electron microscopic studies of the distribution of microtubule-associated protein 2 in rat brain: a difference between the dendritic and axonal cytoskeletons. J Comp Neurol 226:203-221.

Brugg B, Matus A (1991) Phosphorylation determines the binding of microtubule-associated protein 2 (MAP2) to microtubules in living cells. J Cell Biol 114:735-743.

Brunjes PC (1994) Unilateral naris closure and olfactory system development. Brain Res Rev 19:146-160.

Caceres A, Mautino J, Kosik KS (1992) Suppression of MAP2 in cultured cerebellar macroneurons inhibits minor neurite formation. Neuron 9:607-618.

Cobb MH, Boulton TG, Robbins DJ (1991) Extracellular signalregulated kinases: ERKs in progress. Cell Regul 2:965-978.

Crandall JE, Fischer I (1989) Developmental regulation of microtubuleassociated protein 2 expression in regions of mouse brain. J Neurochem 53:1910-1917.

Cummings DM, Brunjes PC (1994) Changes in cell proliferation in the developing olfactory epithelium following neonatal unilateral naris occlusion. Exp Neurol 128:124-128.

Diaz-Nido J, Montoro RJ, Lopez-Barneo J, Aviola J (1993) High external potassium induces an increase in the phosphorylation of the cytoskeletal protein MAP2 in rat hippocampal slices. Eur J Neurosci $5: 818-824$.

Elkabes S, Cherry JA, Schoups AA, Black IB (1993) Regulation of protein kinase $\mathrm{C}$ activity by sensory deprivation in the olfactory and visual systems. J Neurochem 60:1835-1842.

Farbman AI (1992) Cell biology of olfaction. New York: Cambridge University.

Farbman AI, Brunjes PC, Rentfro L, Michas J, Ritz S (1988) The effect of unilateral naris occlusion on cell dynamics in the developing rat olfactory epithelium. J Neurosci 8:3290-3295.

Frazier-Cierpial L, Brunjes PC (1989a) Early postnatal differentiation of granule cell dendrites in the olfactory bulbs of normal and unilaterally odor-deprived rats. Dev Brain Res 47:129-136.

Frazier-Cierpial L, Brunjes PC (1989b) Early postnatal cellular proliferation and survival in the olfactory bulb and rostral migratory stream of normal and unilaterally odor-deprived rats. J Comp Neurol 289:481-492.

Fukunaga K, Soderling TR, Miyamoto E (1992) Activation of $\mathrm{Ca}^{2+} /$ 
calmodulin-dependent kinase II and protein kinase $\mathrm{C}$ by glutamate in cultured rat hippocampal neurons. J Biol Chem 267:22527-22533.

Goto S, Yamamoto H, Fukunaga K, Iwasa T, Matsukado Y, Miyamoto E (1985) Dephosphorylation of microtubule-associated protein 2, tau factor, and tubulin by calcineurin. J Neurochem 45:276-283.

Gray CM, Skinner JE (1988) Centrif ugal regulation of neuronal activity in the olfactory bulb of the waking rabbit as revealed by reversible cryogenic blockade. Exp Brain Res 69:378-386.

Halpain S, Greengard P (1990) Activation of NMDA receptors induces rapid dephosphorylation of the cytoskeletal protein MAP2. Neuron 5:237-246.

Halpain S, Hipolito A, Batinica A, duPont N, Saffer L (1997) Colocalization of calcineurin and F-actin in dendritic spines. Soc Neurosci Abstr 23:1677.

Hendry SHC, Bhandari MA (1992) Neuronal organization and plasticity in adult monkey visual cortex: immunoreactivity for microtubuleassociated protein 2. Vis Neurosci 9:445-459.

Huber G, Matus A (1984) Differences in the cellular distributions of two microtubule-associated proteins, MAP1 and MAP2, in rat brain. J Neurosci 4:151-160.

Illenberger S, Drewes G, Trinczek B, Biernat J, Meyers HE, Olmsted JB, Mandelkow E-M, Mandelkow E (1996) Phosphorylation of microtubule-associated proteins MAP2 and MAP4 by protein kinase

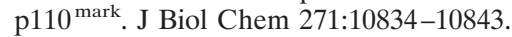

Iwahara S, Oishi H, Sano K, Yang K-M, Takahashi T (1973) Electrical activity of the olfactory bulb in the postnatal rat. Jpn J Physiol 23:361-370.

Jameson L, Caplow M (1981) Modification of microtubule steady-state dynamics by phosphorylation of the microtubule-associated proteins. Proc Natl Acad Sci USA 78:3413-3417.

Kaplan MS, Hinds JW (1977) Neurogenesis in the adult rat: electron microscopic analysis of light radioautographs. Science 197:1092-1094.

Kaplan MS, Mcnelly NA, Hinds JW (1985) Population dynamics of adult-formed granule neurons in the rat olfactory bulb. J Comp Neurol 239:117-125.

Korol DL, Brunjes PC (1990) Rapid changes in 2-deoxyglucose uptake and amino acid incorporation following unilateral odor deprivation: a laminar analysis. Dev Brain Res 52:75-84.

Lois C, Alvarez-Buylla A (1994) Long-distance neuronal migration in the adult mammalian brain. Science 264:1145-1147.

Matus A (1988) Microtubule-associated proteins: their potential role in determining neuronal morphology. Annu Rev Neurosci 11:29-44.

Meisami E (1976) Effects of olfactory deprivation on postnatal growth of the rat olfactory bulb utilizing a new method for production of neonatal unilateral anosmia. Brain Res 107:437-444.

Murphy TH, Blatter LA, Bhat RV, Fiore RS, Wier WG, Baraban JM
(1994) Differential regulation of calcium/calmodulin-dependent protein kinase II and p42 MAP kinase activity by synaptic transmission. J Neurosci 14:1320-1331.

Murthy AS, Flavin M (1983) Microtubule assembly using microtubuleassociated protein MAP2 prepared in defined states of phosphorylation with protein kinase and phosphatase. Eur J Biochem 137:37-46.

Philpot BD, Foster TC, Brunjes PC (1997) Mitral/tufted cell activity is attenuated and becomes uncoupled from respiration following naris closure. J Neurobiol 33:374-386.

Quinlan EM, Halpain S (1996a) Postsynaptic mechanisms for bidirectional control of MAP2 phosphorylation by glutamate receptors. Neuron 16:357-368.

Quinlan EM, Halpain S (1996b) Emergence of activity-dependent, bidirectional control of microtubule-associated protein MAP2 phosphorylation during postnatal development. J Neurosci 16:7627-7637.

Schulman H (1984) Phosphorylation of microtubule-associated proteins by a $\mathrm{Ca}^{2+}$ /calmodulin dependent protein kinase. J Cell Biol 99:11-19.

Sharma N, Kress Y, Shafit-Zagardo B (1994) Antisense MAP-2 oligonucleotides induce changes in microtubule assembly and neuritic elongation in pre-existing neurites of rat cortical neurons. Cell Motil Cytoskeleton 27:234-247.

Sloboda RD, Rudolph SA, Rosenbaum JL, Greengard P (1975) Cyclic AMP-dependent endogenous phosphorylation of a microtubuleassociated protein. Proc Natl Acad Sci USA 72:177-181.

Theurkauf WE, Vallee RB (1983) Extensive cAMP dependent and cAMP independent phosphorylation of microtubule-associated protein 2. J Biol Chem 258:7883-7886.

Tucker RP, Binder LI, Matus A (1988) Neuronal microtubule-associated proteins in the embryonic spinal cord. J Comp Neurol 271:44-55.

Viereck C, Tucker RP, Matus A (1989) The adult rat olfactory system expresses microtubule-associated proteins found in the developing brain. J Neurosci 9:3547-3557.

Walaas SI, Nairn AC (1989) Multisite phosphorylation of microtubuleassociated protein 2 (MAP-2) in rat brain: peptide mapping distinguishes between cyclic AMP-, calcium/calmodulin-, and calcium/ phospholipid-regulated phosphorylation mechanisms. J Mol Neurosci 1:117-127.

Yamamoto H, Fukunaga K, Tanaka E, Miyamoto E (1983) $\mathrm{Ca}^{2+}$ and calmodulin-dependent phosphorylation of microtubule-associated protein 2 and $\tau$ factor, and inhibition of microtubule assembly. J Neurochem 41:1119-1125.

Yamamoto H, Saitoh Y, Fukunaga K, Nishimura H, Miyamoto E (1988) Dephosphorylation of microtubule proteins by brain protein phosphatases 1 and 2A, and its effect on microtubule assembly. J Neurochem 50:1614-1623. 